\title{
QUESTÕES DE GÉNERO E SEXUALIDADE COM CRIANÇAS EM MEIO ESCOLAR: UM ESTUDO COMPARATIVO ENTRE BRASIL E PORTUGAL
}

\author{
Rafaela Gama \\ Doutoranda, CIEC, Instituto de Educação da \\ Universidade do Minho \\ rah.rafaela@gmail.com \\ Zélia Anastácio \\ CIEC, Instituto de Educação da \\ Universidade do Minho \\ zeliaf@ie.uminho.pt
}

Fecha de Recepción: 8 Enero 2019

Fecha de Admisión: 30 Abril 2019

\section{RESUMO}

0 presente artigo é parte de um estudo de doutoramento cuja temática aborda a discussão de questões de género e sexualidade em meio escolar nos países Brasil e Portugal, no âmbito da Educação para a Sexualidade (ES). Visto que o conceito de sexualidade se tem transformado, envolvendo aspetos não só biológicos, mas também históricos, sociais e culturais, entende-se ser importante um trabalho sistemático, permanente e estrutural dessa temática nas escolas. Assim, a ES conquista um papel importante nessa discussão, pois pode favorecer o debate sobre a naturalização e normalização de comportamentos e estereótipos de género, o que pode contribuir também para a prevenção da violência sexual e de género contra crianças e jovens na escola e em diferentes instituições sociais. Nesse sentido, esta proposta de investigação tem como objetivo analisar como o educador de Ensino Fundamental I no Brasil e o educador de 1ํㅡㄴ Ciclo do Ensino Básico (CEB) em Portugal entende as questões de género e sexualidade no cotidiano escolar. Parte-se para uma pesquisa de caráter qualitativo e quantitativo, procurando analisar as legislações e políticas públicas implementadas no âmbito da ES, a opinião e 0 grau de conhecimento dos educadores sobre sexualidade e questões de género e sobre as abordagens dessas temáticas com as crianças, assim como entender como acontece o trabalho sobre sexualidade e questões de género nas escolas Brasileiras de Ensino Fundamental I e Portuguesas de 1.․ㅡ CEB.

Palavras-chave: sexualidade; género; educação; escola; crianças

\section{ABSTRACT}

Gender issues and sexuality with children in school context: a comparative study between Brazil and Portugal. This article is part of a PhD study whose theme approaches the discussion of 
gender issues and sexuality in school context in the countries Brazil and Portugal in the framework of Sexuality Education (SE). Since the concept of sexuality has been transformed, involving not only biological, but also historical, social and cultural aspects, we can understood the importance of a systematic, permanent and structural work about this theme in the schools. Thus, SE acquires an important role in this discussion, as it can encourage the debate on naturalization and standardization of behaviors and gender stereotypes, which may also contribute to the prevention of sexual and gender violence against children and young people at school and in different social institutions. In this sense, this research proposal aims to analyze how the educator of elementary school I in Brazil and the primary school teacher in Portugal understand gender issues and sexuality in school everyday. It is, then, a qualitative and quantitative methodology, seeking to examine the laws and public policies implemented in the framework of SE, the opinion and the degree of knowledge of educators on sexuality and gender issues and the approaches of these themes with children, as well as to understand how happen the work on sexuality and gender issues in Brazilian elementary schools I and Portuguese primary schools.

Keywords: sexuality; gender; education; school; children

\section{INTRODUÇÃO}

As discussões sobre questões de género e sexualidade estão cada vez mais presentes no debate público. Assuntos relacionados com essas questões estão presentes nos meios de comunicação e também em diferentes debates políticos, como a legalização do aborto, a garantia de direitos igualitários para o grupo LGBT e para as mulheres, a presença ou não de políticas educacionais que garantam essas discussões no currículo escolar.

É um debate constante e polémico, onde existe a preocupação de grupos marginalizados na luta contra preconceitos e desigualdades sociais baseadas no género e na sexualidade. Por outro lado, ainda se observa no cotidiano em escolas certa prevalência de estereótipos de género e visões pejorativas face às pessoas que não se enquadram nos padrões de identidade hegemónicos estabelecidos pelas relações de poder existentes na sociedade.

Diversas pesquisas indicam que é comum crianças e jovens que não se encaixam no padrão social de comportamento definido como "normal" sofrerem violência e preconceito também dentro da escola, o que acaba gerando situações de exclusão e, consequentemente, situações de evasão escolar. Nesse sentido, Vieira et al. (2015) afirmam:

As pessoas que não se submetem aos padrões de feminilidades, masculinidades e orientações sexuais encarados como normais, a partir da ótica dos padrões sociais dominantes, são reiteradamente expostas, no ambiente escolar, a violações de direitos, agressões físicas e verbais e discriminações de todo tipo. Suas diferenças convertem-se em reais desigualdades. (p. 1).

Além dessas situações de violência de género, o aumento de denúncias de violência sexual contra crianças tem sido alarmante. Em junho de 2018, no Brasil, a Secretaria de Vigilância em Saúde, ligada ao Ministério da Saúde, publicou um Boletim Epidemiológico da violência sexual contra crianças e adolescentes no país, de 2011 a 2017. Esse estudo indicou que, comparando os anos 2011 e 2017, houve um aumento geral de $83 \%$ nas notificações de violências sexuais, e contra crianças esse aumento foi de 64,6\%. Já em Portugal a Associação de Apoio à Vítima no relatório referente ao ano de 2018, indica 941 casos de vítimas crianças/jovens, com média de idades de 11 anos, sendo $66,7 \%$ do sexo feminino. Embora se destacando a violência doméstica no total dos atendimentos $(77,5 \%)$, no que respeita a crimes sexuais, registaram-se 852 crimes, salientando-se os 348 de abuso sexual de crianças (APAV, 2019).

É na escola que os diferentes modos de ser e estar no mundo se encontram, sendo dever do 
Estado garantir as condições de acesso e de permanência na instituição para todas/os, independente de sua classe social, etnia, cor, orientação sexual ou género (Brasil, 1988; Portugal, 1974). Dessa maneira, existe uma necessidade latente de promover um diálogo mais efetivo sobre questões de género e sexualidade na escola, visando garantir um espaço democrático e de valorização da diversidade.

Desse modo, acredita-se que para a diminuição do preconceito e da violência, além da valorização e do respeito pela diversidade, é necessário um trabalho de base nas escolas. Esse trabalho deve acontecer de maneira sistemática, permanente e estrutural, discutindo questões de género e sexualidade no âmbito da educação para a sexualidade, envolvendo todos da escola.

\section{CONCEITOS DE GÉNERO E SEXUALIDADE E O PAPEL DA ESCOLA}

0 conceito de género surge a partir do que é chamado feminismo de "segunda onda", por volta do final da década de 1960. Nesse momento, o movimento feminista volta-se para construções teóricas, somadas às preocupações sociais e políticas do feminismo de "primeira onda", marcado pela luta ao direito de voto às mulheres no Ocidente do século XIX. Esse conceito buscou destacar 0 caráter social e histórico das diferenciações baseadas no sexo, ou seja, baseadas em características biológicas dos corpos e utilizadas como justificativa para as desigualdades sociais (Louro, 2014).

Já as discussões sobre sexo e sexualidade remontam à Antiguidade, onde se caracterizava por um discurso de controlo dos corpos e dos prazeres ligados a questões religiosas (Salles \& Ceccarelli, 2010). Seguidamente, no século XVII, esse discurso de controlo em volta do sexo e da sexualidade tornou-se regra para as sociedades ocidentais e intensificou-se durante os séculos seguintes, avançando para discussões voltadas ao social (Foucault, 2019). Percebe-se que o conceito de sexualidade está em constante transformação, impulsionada pelas contradições e pela diversidade de ideias existentes na construção do conhecimento. Assim, o que se entende por sexualidade muda ao longo dos séculos, passando por diversas transformações ao longo da história. Em 2006, a World Health Organization (WHO) definiu sexualidade do seguinte modo:

Sexuality is a central aspect of being human throughout life and encompasses sex, gender identities and roles, sexual orientation, eroticism, pleasure, intimacy and reproduction. Sexuality is experienced and expressed in thoughts, fantasies, desires, beliefs, attitudes, values, behaviours, practices, roles and relationships. While sexuality can include all of these dimensions, not all of them are always experienced or expressed. Sexuality is influenced by the interaction of biological, psychological, social, economic, political, cultural, ethical, legal, historical, religious and spiritual factors. (WHO, 2006, p. 5)

Percebe-se que o conceito de sexualidade passou a envolver não apenas aspetos biológicos, mas também sociais, afetivos, psicológicos, entre outros. Nesse sentido, no âmbito escolar, a abordagem biológico-higienista ainda presente na educação sexual no ensino formal é limitante e não alcança outras problemáticas observadas nas relações sociais. Nesse sentido, ao considerar outros aspetos da sexualidade, diversas e importantes discussões surgem, nomeadamente, sobre a violência de género, a equidade de género, os estereótipos de género, a violência sexual. Assim, tornase necessário trazer essas discussões para o cotidiano escolar (Furlani, 2011).

Recentemente, a UNESCO no Brasil reafirmou a importância e a necessidade da legislação brasileira e dos planos de educação incorporarem perspetivas de educação em sexualidade e género, com o objetivo de diminuir a violência e a discriminação (UNESCO, 2016). Esse posicionamento surge devido à onda de violência de género observada em diversos países, sendo o Brasil o país que mais mata travestis e transexuais no mundo (Ayer \& Bottrel, 2017).

No Brasil existem documentos oficiais ligados ao currículo que asseguram e norteiam o traba- 
Iho em Educação Sexual nas escolas e afirmam a importância de uma abordagem integral, onde todos os aspetos que estão envolvidos no conceito de sexualidade são contemplados. Já em Portugal existe a Lei n. 00 de 6 de agosto de 2009, onde as escolas de ensino básico e secundário devem garantir uma carga horária mínima por ano para a Educação Sexual. Todavia, existem diversas problemáticas, no cotidiano das escolas e nas práticas pedagógicas dos professores, que vão na contramão do que é estabelecido nesses documentos.

Nesse sentido, é comum encontrar em conversas com responsáveis por crianças, ou até mesmo professores de escola básica que se sentem inseguros para tratar o tema, discursos que afirmam a importância da educação para sexualidade de crianças, mas ainda com a crença de que seria de responsabilidade apenas da família. Essa situação contraria 0 9.ํ. artigo da Declaração dos Direitos Sexuais, aprovada no 14.․ㅡ Congresso Mundial de Sexologia em Hong Kong, que garante 0 direito à informação baseada na investigação científica (Furlani, 2011), além de ir contra os diversos documentos e políticas internacionais sobre sexualidade e género.

0 conceito de género está relacionado à forma como somos socializados, ou seja, como nossas expectativas, nossos comportamentos e nossas atitudes são constituídos com base no que a cultura atribui como adequado e oportuno ao sexo feminino e ao sexo masculino. Nesse sentido, as questões de género estão presentes na vida de uma pessoa desde antes de nascer. Uma das principais perguntas que são feitas às pessoas que estão à espera de uma criança é se é menina ou menino. A partir daí, na maioria dos casos, todos os objetos como roupa, carrinho, berço, banheira, brinquedos, entre outros, são condicionados a essa questão. E isso continua ao longo de toda a vida da pessoa, em diversos contextos da sociedade.

Numa pesquisa realizada com crianças em França com o objetivo de examinar os pontos de vista das mesmas sobre suas categorizações sexuadas de brinquedos no contexto escolar, MorinMessabel et al. (2016) afirmam que a maioria das crianças persiste em categorizar os brinquedos a partir dos estereótipos associados a masculino e feminino. Além disso, os mais jovens distinguem até os brinquedos menos estereotipados (como os educativos e sem género definido) como de menino ou de menina.

0 género é um conceito complexo, pois baseia-se na construção do papel social de cada sexo. Assim, o género é um conjunto de representações construídas socialmente sobre o que é ser mulher ou homem, atribuindo-se valores sociais distintos a essas práticas e papéis tradicionalmente conferidos de maneira diferenciada (Silva, 2014). Essas características, em geral, estão presentes no processo de socialização da criança, principalmente na escola, o que faz com que a criança reproduza os estereótipos de género e perdurando discursos normativos e direitos sociais desiguais.

Assim, Morin-Messabel et al. (2016) afirmam que a escola se torna um local importante para a desconstrução dos estereótipos, na medida em que oferece brinquedos que são pouco estereotipados ou mistos, principalmente na educação infantil. Portanto, os autores afirmam que é por meio das interações pedagógicas e dos suportes lúdicos que os professores podem fornecer experiências mais heterogéneas, tornando diversos brinquedos e jogos, estereotipados ou menos estereotipados, em mistos, e desconstruindo e questionando a categorização binária entre masculino e feminino.

Além disso, é necessário introduzir a discussão sobre essas questões na escola, no sentido de promover uma educação para a sexualidade integral, além de promover a valorização e o respeito à diversidade. Um exemplo disso é a pesquisa-ação realizada por Xavier Filha (2012) com crianças na faixa etária de 10 a 15 anos numa escola pública municipal na cidade de Campo Grande, Mato Grosso do Sul. Num dos encontros realizados durante a pesquisa-ação, realizou-se a leitura do livro infantil A Menina e o Menino que brincavam de ser..., disparador para discussões sobre as repre- 
sentações de género encontradas na sociedade. Como resultado, a autora afirma que no início da pesquisa-ação as falas das crianças estavam marcadas pelo que é socialmente aceite sobre o que é ser menina ou menino. Assim, investiu-se no questionamento acerca dessas regras e suas origens, discutindo as possibilidades de ser do sujeito.

A autora destaca que as representações de género das crianças são determinadas socialmente e historicamente e, nesse sentido, as ações da pesquisa-ação foram importantes para a problematização desses discursos hegemónicos. Nesse encontro, as crianças estavam abertas a pensar e dar sentidos diferentes às questões de género e às possibilidades múltiplas de construção de suas identidades. Mas essa abertura ao diálogo acontece desde que essas questões sejam discutidas, instigadas e questionadas com elas, afirma a autora. Dessa maneira, talvez possamos garantir que, a médio e a longo prazo, os discursos preconceituosos e excludentes sejam questionados e relativizados e, assim, não sejam reproduzidos.

Sabe-se que as famílias também têm um importante papel na educação sexual da criança e do jovem. Entretanto, em algumas famílias, devido à falta de informação sobre sexualidade e género, ainda são reproduzidos conceções e discursos conservadores e estereotipados sobre educação sexual. Nessa perspetiva, Ostrouch-Kaminska e Chmura-Rutkowska (2015) realizaram uma pesquisa sobre a educação sexual domiciliar de meninos e meninas na Polônia. A análise dos dados qualitativos da pesquisa foi realizada a partir das seguintes categorias: 1) tópicos de conversa entre pais e filhos; 2) fontes de informação sobre sexo; 3) formas de conversa entre pais e filhos sobre sexo; 4) jeitos de se comportar de meninas e meninos; 5) importância da educação sexual domiciliar. Dentro dessas categorias, a pesquisa mostrou que existem diferenças entre a educação sexual domiciliar de garotas e de garotos, baseadas em estereótipos sociais de género. Observou-se que pais (homens) falam menos sobre educação sexual, são menos abertos à discussão e quando 0 fazem é mais comum ser com os filhos e em relação a contraceção e iniciação sexual. Já as mães são mais procuradas para 0 diálogo, principalmente pelas filhas. Pais e mães mantêm, na maioria dos casos, discursos conservadores e estereotipados sobre educação sexual, principalmente em relação ao género dos filhos. Por exemplo, é comumente discutido como meninas e meninos devem ser, como devem se comportar, o que devem gostar, e isso abrange a esfera da sexualidade. Nesse sentido, meninas são educadas a serem mais delicadas, sensíveis e submissas; já os meninos são educados a serem mais agressivos, a esconder suas emoções e a serem competitivos. As autoras encerram 0 artigo afirmando que é essencial a quebra do tabu e do silenciamento na questão da sexualidade e a desconstrução dos estereótipos e ideologias sobre a sexualidade humana e as relações de género. Além disso, destacam que a escola se torna um importante local junto às famílias na superação dessas questões e na promoção de uma educação sexual integral.

As questões de género também estão presentes no mercado de trabalho. Apesar de exaustivas políticas internacionais e nacionais para promoção da equidade entre homens e mulheres nas oportunidades de emprego, salários e condições de trabalho dignos (Silva, 2014), ainda existem violações aos direitos das mulheres em diversas esferas da sociedade. Um exemplo que está relacionado com essas violações contra os direitos da mulher está arrolado a algo comum em décadas passadas: 0 facto de ao casar a mulher cuidar da casa, do marido e dos filhos, sem a possibilidade de trabalhar ou continuar os estudos. Essa situação, em alguns casos, vem acompanhada a violência psicológica e física, principalmente em casos de famílias com baixa renda. Nesse sentido, Tavares e Nery (2016) realizaram um estudo sobre a violência de género e a trajetória educacional de mulheres no Maranhão, Brasil, por meio da entrevista com mulheres que voltam a estudar depois de adultas. Todas essas mulheres entrevistadas vivenciavam ou vivenciaram na época da pesquisa situações de violência durante 0 casamento. 
Por meio da análise das narrativas, as autoras constataram que as condições sociais de pobreza na infância e na adolescência limitavam as possibilidades de estudo dessas mulheres, pois elas necessitavam trabalhar e, geralmente, as escolas eram longe das suas casas. Esses empregos eram (e ainda são), em sua maioria, subempregos, onde aconteciam diversos tipos de explorações, além de terem um retorno financeiro muito baixo. Dessa maneira, essas mulheres assumiam os papéis de género dominantes desde muito jovens, como casar, ter filhos, serem donas de casa. Nesse sentido, o casamento é visto, em alguns casos, como uma oportunidade de uma vida melhor, mas usualmente culmina num processo de dominação e violência física. Assim, o companheiro começa a ter um grande poder de influência em suas escolhas, alegando estar insatisfeito quando a sua companheira possui outras atividades fora do lar.

Dessa forma, as autoras afirmam que existe, dentro desse tipo de relação conjugal, não só uma violência física, mas também uma violência simbólica. Além disso, as autoras afirmam que as falas das mulheres pesquisadas naturalizavam a dominação do companheiro, a imposição do modelo patriarcal e a privação de liberdade de escolha. $E$, em alguns casos, a religião reforça a imagem de submissão da mulher e por conta da ideologia hegemónica essas mulheres têm dificuldade de se reconhecerem numa relação de violência e submissão. As autoras concluem, a partir desses resultados, que não é apenas a violência conjugal que priva as mulheres do estudo, mas o cruzamento do género com a raça/etnia e a classe social. Esses três elementos relacionados fazem com que a mulher obedeça e reproduza o discurso machista. Além disso, afirmam que o patriarcado e a violência de género é um problema político e estrutural da sociedade, sendo necessário o debate, a desconstrução e a desnaturalização desses discursos, requerendo uma intervenção principalmente governamental.

Entretanto, acredita-se que não bastarão leis se:

[...] não houver a transformação de mentalidades e práticas, daí o papel estruturante que adquirem as ações que promovam a discussão desses temas, motivem a reflexão individual e coletiva $e$ contribuam para a superação e eliminação de qualquer tratamento preconceituoso. (Género..., 2009, p. 9).

Nesse sentido, é necessário ir além da discussão e da organização de documentos legais e de ações pontuais sobre essas questões na educação, tornando-se essencial a busca de um trabalho permanente e estrutural nas escolas, que envolva crianças, jovens, professores, gestores, familiares e funcionários. A escola torna-se um importante locus de abordagem e discussão da sexualidade, no sentido de desconstrução e prevenção de estereótipos de género, sexualidade, preconceito e violência.

\section{METODOLOGIA}

Pensando que a escola é um lugar potente de transformação social e de diminuição do preconceito, da violência e das desigualdades, esta pesquisa realiza-se no Brasil e em Portugal com o objetivo principal analisar como 0 educador de Ensino Fundamental I no Brasil e o professor de 1.. CEB em Portugal entende as questões de género e sexualidade no cotidiano escolar.

Parte-se, então, para uma pesquisa de caráter qualitativo e quantitativo, procurando-se analisar as legislações e políticas públicas implementadas no âmbito da Educação para a Sexualidade, a opinião e 0 grau de conhecimento dos educadores sobre sexualidade e questões de género e as abordagens dessas temáticas com as crianças, assim como entender como acontece 0 trabalho sobre sexualidade e questões de género nas escolas de Ensino Fundamental I e 1ํㅡㄹ nos dois países. Para isso, a investigação será dividida em três etapas: fase de diagnóstico, fase de ação/intervenção e fase de avaliação. 
Na primeira fase da investigação-ação, o diagnóstico, pretende-se realizar um levantamento bibliográfico das produções científicas sobre sexualidade e género e das legislações e políticas públicas no âmbito da educação sexual em Portugal e no Brasil. Aplicar-se-á um questionário com educadores do Ensino Fundamental I no Brasil e de 1. CEB em Portugal para levantamento das conceções dos mesmos sobre as questões de sexualidade e género no cotidiano escolar e sobre questões relacionadas à educação sexual.

Na fase de ação, realizar-se-á uma entrevista/formação com um educador no Brasil para levantamento do nível de conhecimento sobre questões de género e sexualidade no meio escolar e perceber como ele entende a educação sexual na escola. Essa entrevista semiestruturada também buscará provocar a reflexão do educador sobre suas conceções e aguçar o seu olhar para as relações no cotidiano da escola. A partir daí, será solicitado ao educador cinco encontros para discussão acerca de temas diversos relacionados às questões de género e sexualidade. Em cada encontro também será realizada uma avaliação de como o educador percebe essas questões no seu cotidiano escolar, trazendo novas reflexões e olhares para essa prática pedagógica. Cada encontro será gravado e transcrito.

Na fase de avaliação realizar-se-á uma segunda entrevista com o educador, para dar voz às suas opiniões e considerações sobre os encontros. Pretende-se também saber se 0 educador percebeu diferenças e transformações nas suas conceções sobre as questões de género e sexualidade no seu cotidiano profissional e se isso implicou mudanças de atitudes no seu fazer pedagógico.

0 projeto cumprirá todas as normativas éticas nacionais e internacionais de investigação, nomeadamente autorizações e sigilo.

Com este projeto espera-se poder delinear um plano de formação e empowerment dos educadores do nível de Ensino Fundamental I / 1. CEB, com vista a contribuir para a minimização dos problemas relacionados com desigualdades de género e ideias preconcebidas e hegemónicas sobre sexualidade, reiterando a importância da educação para a sexualidade nas escolas.

\section{CONSIDERAÇÕES FINAIS}

Tanto nas escolas europeias quanto nas escolas brasileiras a educação sexual surge envolta a um discurso conservador, norteado por valores religiosos e higienistas (Silva \& Megid Neto, 2006). Apesar disso, a escola é pensada e repensada de forma contínua, e cria-se a possibilidade de construir e desconstruir as conceções e preconceitos que nela e por ela são reproduzidos.

Não se pode negar que questões referentes a sexualidade e género estão presentes no cotidiano da escola, nomeadamente nas relações entre estudantes, entre educadores e estudantes, entre educadores, nos discursos e atitudes de cada sujeito da escola. Fazem parte do dia-a-dia, da rotina e também das práticas pedagógicas. É necessário pensar a escola para além de um espaço de normalização dos sujeitos e naturalização e reprodução de preconceitos. É necessário desnaturalizar esses processos e desconstruir discursos que reproduzam as desigualdades encontradas nas relações sociais. Louro (2014, p. 141) elucida que "Alertas para certos comportamentos frequentes nas discussões sobre sexualidade e gênero talvez sejamos mais perspicazes no questionamento de nossa atividade docente. Como vimos, a preocupação 'normalizante' pode ser uma constante.". Também é importante promover uma Educação Sexual que vá além de questões referentes à fisiologia e prevenção de infeções.

Esses processos de desnaturalização e desconstrução são complexos e envolvem repensar também a dinâmica escolar e as relações que são estabelecidas no espaço da escola com todos os que nela se encontram. É iminente discutir estas questões na escola para assim garantirmos uma educação integral de crianças e jovens. 


\section{REFERÊNCIAS}

APAV (2019). Estatísticas APAV. Relatório Anual 2018. Lisboa: APAV

Ayer, F., \& Bottrel, F. (2017). Brasil é país que mais mata travestis e transexuais. Recuperado de http://www.em.com.br/app/noticia/especiais/dandara/2017/03/09/noticia-especial-dandara,852965/brasil-e-pais-que-mais-mata-travestis-e-transexuais.shtml

Brasil. (1988). Constituição da República Federativa do Brasil. (35a ed.). Brasília: Câmara dos Deputados, Edições Câmara. Consultado em Agosto 16, 2016, em http://bd.camara.gov.br/bd/bitstream/handle/bdcamara/.../constituicao_federal_35ed.pdf.

Brasil. (2018). Análise epidemiológica da violência sexual contra crianças e adolescentes no Brasil, 2011 a 2017. Boletim Epidemiológico, 49(27). Brasília: Ministério da Saúde.

Foucault, M. (2019). História da sexualidade: a vontade de saber. São Paulo: Paz e Terra.

Furlani, J. (2011). Educação Sexual na Sala de Aula: relações de gênero, orientação sexual e igualdade étnico-racial numa proposta de respeito às diferenças. São Paulo: Autêntica.

Gênero e Diversidade na Escola: formação de professoras/es em gênero, sexualidade, orientação sexual e relações étnico-raciais. (2009). Rio de Janeiro: CEPESC; Brasília: SPM.

Louro, G. L. (2014). Gênero, sexualidade e educação: uma perspectiva pós-estruturalista. Petrópolis: Vozes,

Morin-Messabel, C., Ferrière, S., Lainé, A., Mieyaa, Y. \& Rouyer, V. (2016). Representações das categorias de sexo em crianças no contexto escolar. Cadernos de Pesquisa, 46(160), 526-546.

Ostrouch-Kaminska, J. \& Chmura-Rutkowska, I. (2015). Home-based sex education: the case of family intergenerational relations in Poland. Ex Aequo, 32, 183-198.

Portugal. (1974). Constituição da República Portuguesa. Consultado em Agosto, 15, 2016, em https://www.parlamento.pt/Legislacao/Documents/constpt2005.pdf.

Salles, A. C. T. da C. \& Ceccarelli, P. R. (2010). A invenção da sexualidade. Reverso, 32(60), 15-24. Consultado em Maio, 8, 2019, em http://pepsic.bvsalud.org/pdf/reverso /v32n60/v32n60a02.pdf.

Silva, P.C.C.da. (2014). Igualdade de género nas autarquias locais: Formação de mainstreaming de género - um estudo de caso. Dissertação de mestrado, Universidade de Coimbra, Coimbra, Portugal.

Silva, R. C. P. da, Megid Neto, J. (2006). Formação de Professores e Educadores para Abordagem da Educação Sexual na Escola: o que mostram as pesquisas. Ciência \& Educação, 12(2), 185197.

Tavares, A.C. \& Nery, I.S. (2016). As repercussões da violência de gênero nas trajetórias educacionais de mulheres. Revista Katál, 19(2), 241-250.

Unesco. (2016). UNESCO no Brasil se Posiciona sobre Questões de Violência de Gênero. 2016. Consultado em Agosto, 25, 2016 em http://www.unesco.org/new/pt/brasilia/about-thisoffice/single-view/news/unesco_in_brazil_stands_against_gender_violence_ issues/\#.V8YOhZgrJNA.

Vieira, V. A., Machado, B. F., Bueno, M. E. \& Lewin, A. P. M. (2015). Gênero e Diversidade Sexual nas Escolas: uma questão de direitos humanos. Carta Capital, 17 jul. 2015. Consultado em Agosto, 15, 2016, em http://www.cartacapital.com.br/sociedade/genero-e-diversidadesexual-nas-escolas-uma-questao-de-direitos-humanos-6727.html.

World Health Organization (WHO). (2006). Defining sexual health. Geneva: World Health Organization. Geneva: OMS.

Xavier Filha, C. (2012). A menina e o menino que brincavam de ser...: representações de gênero e sexualidade em pesquisa com crianças. Revista Brasileira de Educação, 17(51), 627-747. 